\title{
A "systems" perspective on clean technology
}

\author{
Callie W. Babbitt ${ }^{1}$
}

Published online: 9 November 2017

(C) Springer-Verlag GmbH Germany, part of Springer Nature 2017

The question of what makes a technology "clean" is one that has been raised before in this journal (Sikdar 2017). In principle, there is general consensus that assessing environmental performance of a technology must be done using holistic metrics and taking what is often called a "systems" perspective. In other words, recognizing that technologies do not exist in isolation, but rather rely on numerous upstream and downstream processes and activities for their creation and use. Similarly, use of a technology may induce demand for or create impact to interacting systems that are not always readily apparent.

To quantify the environmental implications of these interacting systems, we commonly use methods such as life cycle assessment (LCA). LCA quantifies environmental performance of a technology by accounting for cumulative inputs (energy, water, resources, land) and outputs (emissions, wastes, products) from a system across its entire life: from resource extraction, raw material processing, component and product manufacturing, packaging and delivery, use, and end-of-life (reuse, recycling, disposal). Although many applications of LCA have been demonstrated in this journal (e.g., Diniz et al. 2017, appearing in this issue), it is equally common to see literature that equates clean technology to removal of a single hazard, selection of a bio-based precursor, or creation of a new recycling technology.

The importance and utility of LCA have been underscored by past examples that demonstrate how the lack of a holistic, systems approach may lead to unintended consequences. One example can be seen in the regulatory push to

Callie W. Babbitt

cwbgis@ rit.edu

1 Golisano Institute for Sustainability, Rochester Institute of Technology, Rochester, NY, USA remove lead from solders that are used to connect electronic components to circuit boards in consumer electronic device. As lead is known to create human health risks, it is logical to expect that its removal would lead to lower lead exposure from electronic waste management, particularly if a leadcontaining product was landfilled. However, early life cycle studies on lead-free solder alternatives suggest that these options may require more energy during manufacturing, leading to greater greenhouse gas emissions, and may even potentially increase lead availability and use for other products, such as lead-acid batteries (Ekvall and Andrae 2017).

Replacing hazardous substances, like heavy metals, with more benign alternatives is clearly a central strategy within the domain of Clean Technology and Environmental Policy, but cannot be successfully accomplished without comparing technological risks and benefits at the systems level. A modern example is seen in recent concern regarding solar photovoltaic technologies that contain cadmium (cadmium telluride) or lead (lead perovskite), and whether human or ecological toxicity risks may be created if these metals are released inadvertently. A life cycle perspective is required to compare these risks to those expected for incumbent, fossil-fuel powered electricity production technologies, namely fossil resource demand, high greenhouse gas emissions, acidification potential, and even toxicity associated with combusting coal, which itself contains numerous heavy metals.

Similar examples have played out within public and policy discourse on new technologies. Significant public attention turned to the downsides of compact fluorescent bulbs soon after their introduction. These lighting systems contain mercury, which is rightly viewed as a human health risk, while the incumbent incandescent bulbs do not. However, this view neglected the significant amount of mercury that is generated daily from coal combustion, which makes up 
a sizeable fraction of the electric grid fuel mix in the USA and in many places around the world. From a life cycle perspective, therefore, CFL bulbs actually were more likely to reduce net mercury emissions compared to traditional bulbs because they reduce energy use and thereby the demand for mercury-containing coal combustion (Eckelman et al. 2008). As a result, a more anticipatory approach has been applied to evaluating the next generation of lighting systems-lightemitting diodes (LEDs) — on the basis of comparative life cycle footprints and even potential scarcity risks of rare earth elements used in LED phosphors.

These examples are only a few from a broad and thriving body of literature on LCA methods, applications, and insights. However, despite the consensus that life cycle thinking gives critical insight into sustainable innovation, it is rarely addressed in the environmental rationales used by authors to motivate the need for the "clean" technology their paper presents. Typically, it is taken as fact that a bio-based alternative would be greener compared to a nonrenewable resource, that a waste feedstock is preferable to a primary raw material, or that absence of known hazard automatically ensures that a new technology is "clean." It is far less common to see systematic assessment of such assumptions, even on a qualitative basis, or a parallel investigation of both technical and environmental performances.

This application gap has many factors, most notably the lack of life cycle inventory data with which to characterize environmentally relevant inputs and outputs of emerging technologies. Recent LCA literature has increasingly introduced new tools for life cycle data collection that leverage advances in data mining and computational approaches, process design integrations, spatial modeling tools, and open access dissemination. Often, the complexity of such tools only serves to minimize the likelihood that they are useful to non-specialist LCA users interested in adding systems modeling approaches to traditional empirical or analytical assessment of new technologies. Even greater potential may exist if direct collaboration between knowledge domains can be realized, wherein environmental assessment results provide new inspiration for technological innovation while emerging designs, catalysts, and processes offer practical proving grounds for applying environmental modeling tools. While epistemological barriers to such collaboration may be deeply rooted in the methods, incentives, or structures of traditional techno- or enviro-centric fields, at least one obstacle has already been surmounted: It is clear from reading the pages of this journal that all contributing researchers share a vision and hope for clean technologies that can pave the way for a sustainable future.

\section{References}

Diniz GS, Tourinho TCO, Silva AF, Chaloub RM (2017) Environmental impact of microalgal biomass production using wastewater resources. J Clean Technol Environ Policy. https://doi. org/10.1007/s10098-017-1433-y

Eckelman MJ, Anastas PT, Zimmerman JB (2008) Spatial assessment of net mercury emissions from the use of fluorescent bulbs. Environ Sci Technol 42(22):8564-8570

Ekvall T, Andrae A (2017) Attributional and consequential environmental assessment of the shift to lead-free solders. Int J Life Cycle Assess 11(5):344-353

Sikdar S (2017) Fuzzy clean, fuzzy green. J Clean Technol Environ Policy 19(6):1586-1587 